\title{
KREATIFITAS AKSI PENETRAL SAMPAH GUNA MENETRALISASI KADAR SAMPAH PADA TPA PAKUSARI JEMBER
}

\author{
Azmi Ilmagfiroh* \\ *Progam Studi Tadris Biologi UIN Kiai Haji Achmad Siddiq Jember, Indonesia \\ Email: azmyilma@gmail.com
}

DOI : 10.35719/vektor.v2i2.34

\begin{abstract}
Abstrak. Lingkungan merupakan tempat hidup bagi semua makhluk yang ada di bumi. Lingkungan menjadi faktor terbesar dalam mengetahui derajat kesehatan, sehingga menjaga suatu lingkungan merupakan tanggung jawab bagi setiap masyarakat. Peran masyarakat sangat penting terhadap suatu lingkungan yakni untuk kesehatan manusia, sebab masyarakat dituntut mampu menyelesaikan permasalahan yang menyangkut lingkungan hidupnya. Salah satu permasalahan lingkungan hidup yaitu tentang kebersihan. Kebersihan menjadi sebuah cerminan bagi semua individu manusia dalam menjaga kesehatan. Sampah yaitu zat/ bahan sisa yang sudah tidak terpakai lagi. Selain itu, sampah juga disebut suatu bahan yang terbuang atau dibuang dari sumber hasil aktivitas manusia maupun proses alam yang belum memiliki nilai ekonomis. Sampah ini yang menjadikan masalah disekitar tempat tinggal. Dampak negative dari adanya sampah, antara lain dapat mengakibatkan bencana, penyakit dan kerusakan lingkungan disekitarnya. Hal ini juga diimbangi dengan perilaku manusia sendiri dalam menempatkan sampah. Sampah tidak hanya memiliki dampak negative, tetapi sampah juga memiliki dampah yang positif bagi sekitarnya. Masalah-masalah yang akan dibahas dalam karya tulis ini adalah (1) Mengetahui jenis sampah yang bisa di daur ulang dan sampah yang tidak bisa di daur ulang, dan (2) Proses pembuatan wisata edukasi TPA Pakusari. Dari pembahasan masalah-masalah diatas diharapkan TPA Pakusari menjadi wisata edukasi yang dapat menjadikan solusi bagi masyarakat sekitar, agar sampah tidak hanya menimbulkan dampak negative tetapi juga memiliki dampak yang positif bagi sekitarnya.
\end{abstract}

Kata Kunci: Pengolahan sampah, Sampah, TPA Pakusari

\begin{abstract}
The environment is a place to live for all creatures on earth. The environment is the biggest factor in knowing the degree of health, so protecting an environment is the responsibility of every community. The role of society is very important in an environment, namely for human health, because society is required to be able to solve problems related to the environment. One of the environmental problems is about cleanliness. Cleanliness is a reflection for all human individuals in maintaining health. Waste, namely the remaining substances / materials that are no longer used. In addition, waste is also called a material that is wasted or disposed of from sources of human activity or natural processes that do not have economic value. This garbage is what causes problems around the residence. The negative impact of the presence of waste, among others, can result in disasters, disease and damage to the surrounding environment. This is also offset by human behavior in placing trash. Garbage does not only have a negative impact, but garbage also has a positive impact on the surroundings. The problems that will be discussed in this paper are (1) Knowing the types of
\end{abstract}


waste that can be recycled and waste that cannot be recycled, and (2) The process of making educational tours at Pakusari TPA. From the discussion of the above problems, it is hoped that the Pakusari TPA will become an educational tour that can provide solutions for the surrounding community, so that waste does not only have a negative impact but also has a positive impact on the surroundings.

Keywords: Waste Management, Garbage, Pakusari TPA

\section{PENDAHULUAN}

Lingkungan merupakan tempat hidup bagi semua makhluk yang ada di bumi, khususnya manusia. Lingkungan menjadi faktor terbesar dalam mengetahui derajat kesehatan, sehingga menjaga suatu lingkungan merupakan tanggung jawab besar bagi masyarakat sekitarnya. Peran masyarakat sangat penting terdahap lingkungan untuk menjaga kesehatan manusia, sebab masyarakat dituntut mampu menyelesaikan permasalahan-permasalahan yang menyangkut lingkungan hidupnya. Salah satu dari permasalahan lingkungan hidup yaitu tentang kebersihan. Kebersihan menjadi sebuah cerminan bagi setiap individu manusia dalam menjaga kesehatan. Kebersihan merupakan suatu keadaan yang bebas dari segala kotoran, dan lain sebagainya yang dapat merugikan segala aspek yang menyangkut setiap kegiatan dan perilaku masyarakat. Untuk mewujudkan kebersihan lingkungan, dibutuhkan kesadaran besar dari masyarakat tentang pentingnya menjaga kebersihan lingkungan.

Sampah merupakan bagian dari kehidupan manusia. Sampah yaitu zat/ bahan sisa yang sudah tidak terpakai lagi. Selain itu, sampah juga disebut suatu bahan yang terbuang atau dibuang dari sumber hasil aktivitas manusia maupun proses alam yang belum memiliki nilai ekonomis. (Hartanto, Rudi. 2008) Sampah ini yang menjadikan masalah disekitar tempat tinggal. Dengan jumlahnya yang cukup banyak dan kurang adanya proses pengolahan, maka yang akan terjadi sampah semakin menumpuk, dari dari itu menjadian masalah yang pada lingkungan sekitarnya. Apalagi dengan keadaan sampah yang sulit untuk terurai yang mana membutuhkan waktu yang sangat lama. Bentuk sampah berada dalam beberapa fase materi, yaitu: padat, cair dan gas (Hadnyanawati, H., 2003) Oleh karena itu, adanya sampah harus mendapat perhatian dan penanganan langsung dari masyarakat yang sangat serius.

Stigma masyarakat terhadap sampah yaitu semua sampah itu menjijikkan, kotor, dapat menimbulkan penyakit dan lain-lain sehingga harus ada penetralisasi agar sampah tidak terbilang menjijikan, kotor bahkan dapat menimbulkan penyakit. Adapun cara agar sampah dapat di netralisasi biasanya dengan cara dibakar ataupun dibuang, dibuang ini juga harus memperhatikan tempat dan kondisi agar tidak mencemari lingkungan khususnya tanah. Yakni yang dengan sebagai mana mestinya dibuang ditempat yang memang tidak terjangkau dengan lingkungan bersih, agar lingkungan yang bersih tidak tercemar oleh sampah akibat pembuangan tadi (Mulasari S.P, 2012). Segala aktivitas masyarakat selalu saja menimbulkan sampah. Menurut UU no 18 Tahun 2008 pengolahan sampah didefinisikan sebagai perubahan bentuk sampah dengan perubahan karakteristik, komposisi dan jumlah sampah (Balai teknik air minum dan sanitasi wilayah. 2010). Oleh karena itu, hal ini tidak menjadi salah satu tanggung jawab pemerintah tetapi juga menjadi tanggung jawab seluruh masyarakat yang bertempat di daerah tersebut untuk mengolah sampah agar tidak berdampak negatif bagi kehidupan dan lingkungan sekitar (Hardiatmi S. 2010).

Masalah yang sampai saat ini masih terbilang tinggi dan harus memiliki penanganan secara optimal yaitu sampah. Sampah telah menjadi masalah dikota 
maupun diperdesaan. Apalagi ketika sampah tidak dikelola dengan sebaik mungkin, maka akan mengakibatkan suatu dampak, mulai dari dampak jarak pendek sampai dengan dampak jarak panjang. Dampak inilah yang akan dirasakan oleh manusia, baik masyarakat yang ada disekitar tempat tersebut maupun yang jauh sekalipun dari area tumpukan sampah. karena sampah tidak bisa dipungkiri lagi suatu saat nanti akan memberikan dampak yang buruk bagi kesehatan bahkan lingkungan, apalagi ketika tidak dapat diolah dengan semaksimal mungkin. Selain itu, sampah ini akan memiliki dampak mulai dari yang kecil hingga akan berdampak pada semua yang ada disekitarnya.

Masalah yang sampai saat ini masih terbilang tinggi dan harus memiliki penanganan secara optimal yaitu sampah. Sampah telah menjadi masalah dikota maupun diperdesaan. Apalagi ketika sampah tidak dikelola dengan sebaik mungkin, maka akan mengakibatkan suatu dampak, mulai dari dampak jarak pendek sampai dengan dampak jarak panjang. Dampak inilah yang akan dirasakan oleh manusia, baik masyarakat yang ada disekitar tempat tersebut maupun yang jauh sekalipun dari area tumpukan sampah. karena sampah tidak bisa dipungkiri lagi suatu saat nanti akan memberikan dampak yang buruk bagi kesehatan bahkan lingkungan, apalagi ketika tidak dapat diolah dengan semaksimal mungkin. Selain itu, sampah ini akan memiliki dampak mulai dari yang kecil hingga akan berdampak pada semua yang ada disekitarnya.

Sampah berdampak pada pulusi udara, seperti halnya bau sampah yang tidak sedap akan menggangu orang di sekitar TPA tersebut, selain itu apabila terjadi pembakaran sampah maka asap dari pembakaran tersebut juga akan menimbulkan masalah baru bagi lingkungan. Dengan demikian lingkungan akan dipenuhi oleh asap sampah dan nantinya asap tersebut akan menjadikan polusi yang dapat menyerang kesehatan masyarakat. Selain itu, dengan banyaknya udara yang kotor maka masyarakat sekitar akan kekurangan oksigen yang bersih. Hal ini mengakibatkan dampak yang sangat buruk bagi kesehatan. Oleh karena itu, pengelolahan sampah untuk menghilangan bau dan menjadi polusi udara dari hasil pembakaran sampah tersebut sangalah perlu agar tidak berdampak pada yang lebih serius.

Dampak sampah selanjutnya yaitu dapat mengakibatkan tanah menjadi tercemar. Tanah yang tercemar yaitu tanah yang sudah tidak sehat lagi, mengandung bahan-bahan yang berbahaya bagi kesehatan. Tanah yang tercemar menjadikan tanah yang biasa digunakan oleh petani untuk menanam menjadi tidak subur, dan tumbuhan pun tidak akan hidup dengan maksimal yang dapat menghasilkan sumber pangan bergizi. Dengan demikian para petani akan mengalami kegagalan dalam penanaman pada lahannya. Selain itu, dari adanya pembakaran sampah yang dilakukan untuk meminimalisir sampah dan adanya tumpukan sampah yang mengandung bahan kimia maka bahan kimia akan turun kebawah yakni ke tanah. Hal tersebut yang menjadikan dampak juga bagi tanah yakni dari pembakaran sampah dan tumpukan sampah tersebut tanah akan menjadi tidak subur karena sudah tercampur dengan bahanbahan kimia lainnya.

Adanya dampak sampah bagi air, yakni terjadinya pencemaran air yang mana air yang terkena sampah sudah tidak dapat digunakan lagi, baik dalam hal untuk kebutuhan bersih-bersih apalagi digunakan untuk kebutuhan cairan bagi tubuh seperti minum karena memang air pada kondisi itu sudah tidak sehat lagi. Air tersebut pastinya sudah tercampur dengan bahan-bahan lain seperti halnya bahan kimia yang terdapat pada tumpukan sampah dan ditambah dengan adanya tanah yang tercemar. Maka dari itu, dapat disimpulkan bahwanya kondisi air yang tidak layak lagi untuk dipakai berarti air itu sudah tercemar. Maka hal jangka pendeknya masyarakat akan lebih kesulitan untuk mendapatkan air yang bersih yang tidak tersemar oleh sampah. 
padahal air menjadi sumber utama dalam suatu kehidupan, karena tanpa air maka semua kegiatan tidak bisa maksimal.

Selain dampak pencemaran tersebut, adanya sampah maka akan menimbulkan bencana, seperti halnya banjir. Banjir terjadi akibat adanya luapan air akibat adanya sungai yang tersumbat oleh sampah, akibatnya air yang seharusya dapat mengalir makadengan adanya sampah air tidak bisa mengalir dengan lancar, dari hal itu sampah dapat menjadikan bencana juga bagi manusia. dan tanah longsor pun juga akan menjadi dampak adanya sampah, biasanya tanah longsor terjadi di pegunungan. Selain itu, dampak pencemaran oleh sampah pada udara, air dan tanah maka akan berakibat juga kepada kesehatan masyarakat terkena penyakit, dari penyakit yang biasa juga bisa menjadikan penyakit yang fatal dan harus di waspadai. Penyakit dari adanya sampah yang ada dimana-mana menjadikan pola hidup tidak sehat dari itu dapat mengakibatkan tifus, disentri dan diare.

Permasalahan ini sudah ada sejak jaman dahulu kala. Ketika seseorang sudah mulai bertempat tinggal menetap pasti disitu akan menghasilkan sampah. dari sampah itu maka akan menimbulkan masalah. Akan tetapi permasalahan sampah tidak sebesar saat ini. Karena orang pada jaman dahulu menerapkan sistem proses pengelolaan sampah seperti pembuangan, pembakaran, recyicling, atau pengurangan pemakaian bahan. Sama seperti saat ini, manusia masih menggunakan proses mengelolaan sampah tersebut. akan tetapi kini sampah menjadi masalah sangat besar. Karena yang kita ketahui bahwa saat ini sampah berceceran, dimanapun tempat pasti terdapat sampah. selain itu, pada zaman dahulu masyarakat masih tergolong patuh terhadap lingkungannya. Berbeda dengan sekarang orang-orang banyak yang tidak memikirkan lingkungannya, hanya memikirkan nafsunya dan tidak bisa mengolahnya.

Sampah berdasarkan bahan asalnya, dapat dibedakan menjadi dua jenis, yaitu sampah organic dan sampah non organic. Begitupun yang sudah diterapkan oleh Negara yang memilah antara sampah organic dan non organic. Sampah ini kemudian akan dibuang di TPA (Tempat Pembuangan Sampah Akhir). Menurut Peraturan Menteri Dalam Negeri Nomer 33 Tahun 2010 tentang Pengelolahan Sampah (Permendagri No. 33 Tahun 2010) dan beberapa peraturan Menteri Lingkungan Hidup dan Menteri Pekerjaan Umum yang merupakan Peraturan Pelaksana Dari Undang-Undang Nomer 18 Tahun 2008 tentang pengelolahan sampah muncul singkatan TPS (Tempat Penampungan Sementara) dan TPA (Tempat Pemrosesan Akhir) akhirnya muncul dalam peraturan tersebut. Pengertian TPS sendiri yaitu tempat sebelum sampah diangkut ketempat pendauran ulang, mengolahan, dan atau tempat mengolahan sampah terpadu. Sedangkat pengertian TPA sendiri yaitu tempat pemrosesan akhir, yaitu tempat untuk memproses dan mengembalikan sampah ke media lingkungan secara aman bagi manusia dan lingkungan.

Pada TPA dilakukan macam kegiatan untuk memproses adanya sampah tersebut, agar sampah tidak merusak lingkungan bahkan meimbulkan penyakit yang akan terkena masyarakat sekitar. Beberapa macam kegiatan yang dilakukan di TPA sampah antara lain menutup sampah dengan tanah secara berlapis, serta mengelola menjadi hal yang baru yang dapat dipakai kembali oleh masyarakat sekitar, dan akhirnya proses daur ulang gas ini memjadikan manfaat bagi kehidupan manusia seperti halnya air lindi dan gas metana yang dihasilkan dari pengelolaan sampah tersebut. konsep yang diterapkan kedalam TPA yaitu konsep 3R (Reduce, reuse dan recycle) harus dipopulerkan hingga tertanam dikesadaran pribadi warga kota maupun desa. Setidaknya warga sekitar sadar untuk melakukan pemilihan sampah. 
Sampah dipilah menurut klasifikasinya terbagi menjadi tiga bagian, yaitu sampah organic, sampah anorganic dan sampah B3 (bahan berbahaya dan beracun).

Sampah organic yaitu sampah yang berasal dari makhluk hidup, baik dari manusia, hewan dan tumbuhan. Sampah organic juga terbagi menjadi dua kategori seperti sampah organic basah dan sampah organik kering. Untuk sampah organic basah yaitu sampah yang memiliki kandungan air yang cukup tinggi. Selain itu mudah diuraikan mikroorganisme tanah dan apabila tidak dikelola secara baik maka dapat menimbulkan bau tak sedap. Contohnya sayur-sayuran, buah-buahan yang sudah busuk, sisa nasi, dedaunan dan lainnya. Sampah organic kering merupakan sampah organic yang memiliki kandungan air sedikit. Contohnya kayu, ranting, pohon dan daun kering.

Sampah anorganik yaitu sampah yang tidak bisa diperbarui, seperti minyak bumi, mineral atau dari proses industry. Secara keseluruhan sampah ini tidak dapat diuraikan oleh alam, sedangkan sebagian lainnya bisa diuraikan akan tetapi dalam kadar waktu sangat lama. Seperti contohnya sampah rumah tanggal, yaitu botol, plastic, dan kaleng.

Sampah B3 (Bahan Berbahaya dan Beracun) marupakan sampah yang dikategorikan berbahaya dan beracun bagi manusia. Sampah jenis ini biasanya banyak yang mengandung merkuri seperti halnya pada kaleng bekas minyak wangi atau cat semprot. Akan tetapi juga tidak bisa dipungkiri lagi bahwa bahan-bahannya juga mengandung zat beracun lainnya yang lebih berbahaya. Dari macam-macam sampah yang dikemukakan diatas pada hakikatnya sampah dapat terbentuk memalui proses kimia, biologis dan fisik, karena kesalahan dan ketidakoptimuman proses yang berlangsung dalam mengolah bahan baku primer dan skunder (Nurhidayat, S. 2002)

Sampah memiliki dampak bagi lingkungan sekitarnya. Baik dampak positif maupun dampak negative yang terdapat pada sampah tersebut. Apabila sampah diolah dengan pengelolaan yang cukup baik maka akan berdampak baik. Selain itu juga mencerminkan sikap positif bagi masyarakat dan juga lingkungannya, seperti: sampah dapat bermanfaat untuk menimbun lahan seperti rawa-rawa atau dataran rendah, sampah dimanfaatkan sebagai pupuk, dan menurunkan insidensi kasuspenyakit menular yang erat hubungannya dengan masalah sampah (Chandra, B. 2007) Dekpes (1997) dalam Guntar (1999) (Dekpes RI.1997) menyebutkan sampah yang tidak dikelola dengan baik, maka akan mengakibatkan dampat tidak baik juga bagi masyarakat dan lingkungan sekitarnya. Seperti, estetika lingkungan kurang enak dipandang mata, adanya penyakit dari hubungan erat sampah tersebut, dan lingkungan yang rusak dan dapan mengakibatkan bencana.

Dari dampak yang banyak ditimbulkan oleh sampah, penulis melihat adanya dampak negative maka akan menjadikan lingkungan dan masyarakat sekitarnya memiliki masalah-masalah seputar sampah tersebut. Maka dari itu, penulis berinisiatif untuk menggali lebih dalam informasi tentang TPA Pakusari yang menjadi tempat edukasi. Yakni hal ini, menjadi salah satu usaha yang dilakukan untuk meminimalisir masalah sampah. Tidak hanya untuk meminimalisir keadaan sampah akan tetapi untuk mengembangan edukasi yakni dengan mengetahui proses pengolahan sampah yang telah digunakan pada TPA pakusari. 


\section{METODE}

Dalam metode penelitian kali ini yakni menggunakan analisis SWOT, dengan ini akan mengetahui bagaimana keadaan yang terjadi di TPA Pakusari saat ini. Analisis SWOT yaitu suatu metode perencanaan strategis yang digunakan untuk mengavaluasi factor-faktor yang terjadi. Analisis SWOT meliputi kekuatan (strengths), kelemahan (weaknesses), peluang (opportunities), dan ancaman (threats). Teknis analisis data menggunakan analisis SWOT yakni untuk menganalisis factor-faktor internal pada TPA Pakusari dengan menjadikan apasaja dari kelemahan dan kekuatan dari TPA Pakusari. Untuk factor eksternal meliputi ancaman dan peluang dalam masyarakat. Dalam melakukan analisis SWOT, tahapan yang digunakan sebagai berikut: a) Identifikasi factor-faktor internal dan eksternal, b) Penyusunan kuesioner dan c) analisis data.

\section{HASIL DAN PEMBAHASAN}

TPA Pakusari yang saat ini sudah menjadi wisata edukasi. TPA yang dulunya bersifat parasit dan menimbulkan banyak kerugian bagi lingkungan dan masyarakat sekitar kini telah berubah 100\%. Dengan mengandalkan pemerintahan dan masyarakat sekitar kini mampu merubahan kawasan pakusari tersebut dengan menjadikan wisata edukasi. Yakni edukasi yang dipaparkan tentang mengelolaan sampah yang terdapat pada TPA Pakusari. Seperti halnya proses daur ulang sampah anorganik yang terdapat pada TPA tersebut, dan akan menghasilkan barang yang baru dan dapat digunakan kembali, tanpa harus menggunakan pembuatan barang yang baru. Barang ini akan bersifat efektif dan ekonomis, karena menggunakan metode pengolahan sampah daur ulang.

Untuk pengelolaan sampah dengan kadar air yang banyak atau disebut sampah organic pada wisata edukasi ini menggunakan solusi dengan pembuatan pupuk kompos. Pupuk kompus yaitu pupuk yang didasarkan dengan sisa-sisa buah atau sayuran, selain itu juga bisa dari dedaunan yang sudah rontok tak hanya menjadi sampah akan tetapi dapat juga di gunakan untuk pupuk. Pupuk dengan pengolahannya yang sangat mudah hal ini bisa digunakan untuk pupuk tumbuhan tanpa harus menggunakan bahan kimia yang pasti memiliki dampah negative atau kadar bahaya bagi lingkungannya. Adapun alat dan bahan dalam pembuatan pupuk kompos tersebut yaitu:

1. Wadah berukuran besar dengan disertai penutupnya (ember atau tong)

2. Sarung tangan

3. Sampah rumah tangga

4. Tanah

5. Air berikut:

Untuk pengolahan pupuk organic juga memiliki proses tertentu. Yakni sebagai

1. Siapkan sampah organic yang berasal dari sampah rumah tangga

2. Kemudian siapkan wadah berukuran besar untuk tempat pembuatan pupuk dilengkapi dengan bawahnya memiliki penutup agar sampah tidak terkontaminasi

3. Masukan tanah secukupnya sesuai dengan banyak sampah

4. Siram permukaan tanah dengan menggunakan air secukupnya

5. Masukan sampah organic kedalam wadah yang sudah terisi tanah tersebut 
6. Sampah disimpan secara merata sesuai dengan ketebalan dari tanah sebelumnya

7. Kemudian masukan tanah lagi ke wadah tersebut, hal ini berperan untuk penutup sampah

8. Setelah itu, tutup wadah dengan rapat dan dibiarkan sekitar tiga minggu

9. Sampah berhasil menjadi pupuk kompos yang siap digunakan

Yang selanjutnya, sampah organic dapat dilakukan dengan pengolahan biogas yakni bahan kompor gas seperti elpiji. Biogas merupakan bahan bakar gas yang dihasilkan oleh aktifitas anaerobic atau fermentasi dari bahan-bahan organic termasuk diantaranya kotoran manusia dan hewan, limbah domestic (rumah tangga) atau degradasi anaerobic bahan-bahan organic oleh bakteri-bakteri anaerobic. Metana dalam biogas, bila terbakar akan relative lebih bersih disbanding dengan batu bara, dan menghasilkan energy yang lebih besar dengan emisi karbon dioksida yang lebih sedikit.

Biogas di definisikan sebagai gas yang dilepaskan jika bahan-bahan organic (seperti kotoran hewan, kotoran manusia, jerami, sekam, dan sayur-sayuran) difermentasi atau mengalami proses metanisasi. Biogas terdiri dari campuran metana (50-75\%) $\mathrm{CO}_{2}(25-45 \%)$, serta sejumlah kecil $\mathrm{H}_{2}, \mathrm{~N}_{2}$ dan $\mathrm{H}_{2} \mathrm{~S}$.

\begin{tabular}{|c|l|c|}
\hline NO & \multicolumn{1}{|c|}{ Jenis Gas } & $\begin{array}{c}\text { Campuran Kotoran } \\
\text { + Sisa Pertanian }\end{array}$ \\
\hline $\mathbf{1}$ & Metana $\left(\mathrm{CH}_{4}\right)$ & $54-70 \%$ \\
\hline $\mathbf{2}$ & Karbon dioksida $\left(\mathrm{CO}_{2}\right)$ & $27-45 \%$ \\
\hline $\mathbf{3}$ & Nitrogen (N2) & $0,5-3 \%$ \\
\hline $\mathbf{4}$ & Karbon Monoksida $(\mathrm{CO})$ & $0,1 \%$ \\
\hline $\mathbf{5}$ & Oksigen (O2) & $0,1 \%$ \\
\hline $\mathbf{6}$ & Propen (C3H8) & - \\
\hline $\mathbf{7}$ & Hidrogen Sulfida $(\mathrm{H} 2 \mathrm{~S})$ & Sedikit Sekali \\
\hline $\mathbf{8}$ & Nilai Kalori $\left(\mathrm{Kcal} / \mathrm{m}^{3}\right)$ & $4800-6700$ \\
\hline
\end{tabular}

Tabel 1. Komposisi gas dalam Biogas

Biogas merupakan campuran gas yang dihasilkan oleh bakteri metanogenetik yang terjadi pada material-material yang dapat terurai secara alami dalam kondisi anaerobic, pada umumnya biogas terdiri atas gas metana $\left(\mathrm{CH}_{4}\right) 50$ sampai $70 \%$, gas karbon dioksida $\left(\mathrm{CO}_{2}\right) 30$ sampai $40 \%$, Hidrogen ( $\left.\mathrm{H} 2\right) 5$ sampai $10 \%$ dan gas-gas lainnya dalam jumlah yang sedikit. Komposisi gas yang terkandung di dalam biogas dapat dilihat pada Tabel 2. 


\section{Komponen}

$\%$ Volum

\begin{tabular}{lc}
\hline Metana $\mathrm{CH} 4$ & $55-75$ \\
Karbon dioksida $\left(\mathrm{CO}_{2}\right)$ & $25-45$
\end{tabular}

$\begin{array}{lc}\text { Nitrogen (N2) } & 0-0,3 \\ \text { Hidrogen (H2) } & 1-5\end{array}$

Hidrogen Sulfida (H2S) $\quad 0-3$

Oksigen (O2) $\quad 0,1-0,5$

Tabel 2. Komposisi Biogas

Untuk pembuatan biogas di perlukan alat dan bahan sebagai berikut:

1. pipa berpori-pori

2. tanah

3. sampah organic

4. reactor biogas

5. blower

Sedangkan, Proses pembuatan biogas sebagai berikut:

1. hanya dengan memasukan pipa berpori-pori kedalam tumpukan sampah

2. kemudian ditutup dengan tanah untuk menagkap gas metan.

3. Selanjutnya apabila gas metan sudah tertangkap maka akan disalurkan ke reactor biogas untuk memisahkan gas dan air.

4. Gas yang sudah terpisah kemudian disalurkan melalui pipa yang didorong ke sumber pemakaian blower.

5. Gas metana siap digunakan

Hasil dari reaksi tersebut kemudian di salurkan hingga kompor menyala seperti elpiji. Untuk instalasi TPA Pakusari memiliki 2 titik, yaitu satu titik dimanfaatkan sendiri, terutama sebagai kegiatan edukasi dan satu titik disalurkan menggunakan pipa ke 20 kapala keluarga yang berada disekitar TPA Pakusari. Hal ini akan lebih efektif yakni, tanpa harus membeli gas elpiji akan tetap bisa memasak. Wisata edukasi ini mengajarkan banyak pengolahan sampah yang belum diketahui dan dianggap remeh bagi masyarakat seperti halnya daur ulang sampah tanpa adanya proses dalam daur ulang tersebut, akan menjadikan suatu barang yang baru dan dapat digunakan kembali.

Daur ulang sampah yaitu proses untuk menjadikan suatu bahan bekas menjadi bahan baru yang dengan memiliki tujuan tersentu yaitu mencegah adanya sampah yang aslinya dapat menjadi barang yang berguna, mengurangi penggunaan energy, mengurangi polusi, kerusakan lahan, dan emisi gas rumah kaca jika dibandingan dengan proses pembuatan barang baru. Daur ulang adalah salah satu strategi pengelolaan sampah padat yang terdiri atas kegiatan pemilahan, pengumpulan, pemrosesan, pendistribusian dan pembuatan produk atau material bekas pakai, dan 
komponen utama dalam management sampah modern dan bagian ketiga dalam proses hierarki sampah 4R (Reduce, Reuse, Recycle dan Replace). Materian ini biasanya terdiri dari sampah-sampah yang padat yang masih dapat digunakan kembali seperti sampah kaca, plastic, kertas, logam, tekstil, dan barang elektronik. Akan tetapi dalam TPA pakusari biasanya untuk mendaur ulang dari bahan-bahan seperti plastic, kertas, dan kaca. Karena sampah ini yang biasa dipakai masyarakat atau ibu rumah tangga dalam melakukan kegiatan nya sehari-hari. kreatifitas memanglah menghasilkan banyak kegiatan, seperti halnya kreatifitas tangan dalam melakukan proses daur ulang sampah. dari bentuk sampah yang semula hanya palastik-plastik yang sudah terbuang, hal itu juga bisa dijadikan berbagai macam bahan baru yang tentunya tidak kalah menariknya. Seperti halnya dan aksesoris-aksesoris dengan berbagai macam karakter yang dapat dipakai kembali.

Penerapan wisata edukasi di TPA Pakusari perlu memperhatikan aspek-aspek penting dalam melihat keefektifan sampai saat ini. Edukasi yang di terapkan dalam TPA PAkusari itu juga harus memberikan efek samping bagi para pangunjung. Agar pengunjung tidak hanya melihat-lihat keindahan sekitar akan tetapi memperoleh ilmu dari adanya proses-proses dari kegiatan tersebut. selain itu, suatu kegiatan pasti memiliki penerus untuk mengembangan kegiatan tersebut, oleh karena itu diharapkan setelah datang di tempat edukasi TPA Pakusari ini para masyarakat dapat iku andil dalam proses-proses kegiatan seperti pembuatan kompos, biogas bahkan daur ulang. Dari itu, generasi muda sangatlah penting dalam sebuah organisasi untuk mengembangkan kegiatan yang sudah ada.

Aspek penting tersebut dapat dikaji dengan menggunakan analisis SWOT yaitu Strengthes (Kekuatan), Weakneasses (Kelemahan), Oppurtinities (Peluang), and Threats (Ancaman) dan disajikan dalam tabel berikut :

\begin{tabular}{|c|c|}
\hline $\begin{array}{l}\text { Strengthes } \\
\text { - Terdapat pembelajaran yang diajarkan } \\
\text { tentang pengelolaan sampah. } \\
\text { - Terdapat praktek dari pengelolaan } \\
\text { sampah. } \\
\text { - Menjadikan wisata yang berguna } \\
\text { untuk menambah wawasan } \\
\text { - Meminimalisir penumpukan sampah } \\
\text { - Meminimalisir penyakit dan kerusakan } \\
\text { lingkungan pada kawasan TPA } \\
\text { Pakusari }\end{array}$ & $\begin{array}{l}\text { Weakneasses } \\
\text { - Barang yang didapat tidak } \\
\text { memiliki mutu yang sangat baik } \\
\text { seperti barang baru } \\
\text { - Masyarakat yang kurang sadar } \\
\text { atas pentingnya pengelolaan } \\
\text { sampah dan belum bisa ikut andil } \\
\text { dalam mengelola sampah }\end{array}$ \\
\hline $\begin{array}{l}\text { Oppurtinities } \\
\text { - Target sasaran kepada anak-anak } \\
\text { muda agar menjadi kreatif } \\
\text { - TPA Pakusari menjadi bersih dan indah } \\
\text { - Anak sekarang suka berwisata }\end{array}$ & $\begin{array}{l}\text { Threats } \\
\text { - Terdapat produk sejenis yang } \\
\text { dihasilakn dari sampah } \\
\text { - Wisata ini tidak akan berkembang } \\
\text { tanpa adanya generasi muda }\end{array}$ \\
\hline
\end{tabular}

Tabel 3. Analisis SWOT untuk wisata edukasi di TPA Pakusari

Analisis SWOT menjadi dasar peneliti untuk merumuskan permasalahan yang ada agar dapat meminimalkan kerugian. Selain itu, untuk analisis kelemahan dan ancaman dari wisata edukasi ini tentunya harus segera ditanggapi agar tidak terdapat masalah yang menjadikan wisata ini berhenti atau tidak berkembang. Oleh sebab itu, 
diperlukan solusi yang membangun agar kelemahan dan ancaman yang sudah ada dapat ditekan agar kekuatan dan peluang dapat unggul.

\section{KESIMPULAN}

Adanya wisata edukasi ini memberikan peluang besar bagi masyarakat terutama anak muda untuk mengetahuai cara-cara pengolahan sampah. seperti halnya proses dalam pembuatan pupuk kompus yang digunakan untuk memupuk tanaman, biogas yang bermanfaat untuk memasak bagi ibu rumah tangga jadi tidak usah mengeluarkan uang sepersen pun, dan daur ulang yakni proses pendauran ulang dari barang bekas menjadi barang yang baru dengan bentuk yang baru pula.

Adanya pembelajaran tentang proses pembuatan seperti pupuk kompos, biogas maka akan menambah pengetahuan yang dapat dipakai pada kehidupan sehari-hari. Bertambahnya pengetahuan dapat juga menggugah agar pemuda dapat mengolah sampah dengan tangan kreatif pemuda. Selain itu, adanya Wisata edukasi ini maka meminimalisir adanya dampak negative dari sampah, selain itu memberikan dampak positif bagi lingkungan dan masyarakat.

Terdapat analisis SWOT yang akan memberikan pemahaman tentang efektifnya Wisata Edukasi bagi warga sekitar terutama pemuda yang harus bisa memberikan dampak positif dengan adanya sampah.

\section{DAFTAR PUSTAKA}

Hartanto, Rudi. 2008. Penanganan dan Pengolahan Sampah. Bogor: Seri industry kecil.

Hadnyanawati, H. 2003. Pengolahan sampah. Universitas Jember. Jember.

Nurhidayat, S. P. 2002. Pengolahan Sampah Untuk Pupuk dan Pestisida Organik. Penabar Swadaya. Depok.

Chandra, B. 2007. Pengantar Kesehatan Lingkungan, Penerbit Buku Kedokteran EGC: Jakarta

Dekpes RI. 1997. Pemberantasan Lalat. Jakarta: Ditjen PPM dan PLP

Mulasari S.P. (2012). Hubungan Tingkat Pengetahuan Dan Sikap Terhadap Perilaku Masyarakat Dalam Mengelola Sampah Jurnal Kesmas Volume 6 nomor 3: $204-$ 211

Materi pelatihan berbasis kompetensi bidang persampahan (Balai teknik air minum dan sanitasi wilayah. Surabaya, 2010

Hardiatmi S. (2011) Pendukung Keberhasilan Pengolahan Sampah Kota. INNOFARM. Jurnal Inovasi Pertanian, 10 (1): 50-66

Peraturan Menteri Dalam Negeri Nomor 33 Tahun 2010 tentang Pengelolahan Sampah

Pertiwiningrum, Ambar. 2015. Intalasi Biogas. Universitas Gadjah Mada Yogyakarta: Cv. Kolom Cetak 